\title{
THEORETICAL \\ ACOUSTICS OF \\ UNDERWATER \\ STRUCTURES
}


This page is intentionally left blank 


\section{THEORETICAL}

ACOUSTICS OF

UNDERWATER

\section{STRUCTURES}

\section{E A Skelton}

Imperial College, UK

J H James 


\section{Published by}

Imperial College Press

516 Sherfield Building

Imperial College

London SW7 2AZ

\section{Distributed by}

World Scientific Publishing Co. Pte. Ltd.

P O Box 128, Farrer Road, Singapore 912805

USA office: Suite 1B, 1060 Main Street, River Edge, NJ 07661

UK office: 57 Shelton Street, Covent Garden, London WC2H 9HE

\section{British Library Cataloguing-in-Publication Data}

A catalogue record for this book is available from the British Library.

\section{THEORETICAL ACOUSTICS OF UNDERWATER STRUCTURES}

\section{Copyright $(\mathcal{C} 1997$ by Imperial College Press}

All rights reserved. This book, or parts thereof, may not be reproduced in any form or by any means, electronic or mechanical, including photocopying, recording or any information storage and retrieval system now known or to be invented, without written permission from the Publisher.

For photocopying of material in this volume, please pay a copying fee through the Copyright Clearance Center, Inc., 222 Rosewood Drive, Danvers, MA 01923, USA. In this case permission to photocopy is not required from the publisher.

ISBN $\quad 1-86094-085-4$

This book is printed on acid-free paper. 


\section{CONTENTS}

PREFACE $\quad$ xi

ACKNOWLEDGEMENTS Xiii

INTRODUCTION $\quad 1$

1 MATHEMATICAL METHODS $\quad 7$

1.1 Fourier Series . . . . . . . . . . . . . . . . . . 7

1.2 Fourier Transforms . . . . . . . . . . . . . . . . . . . . . . 9

1.3 Delta Functions . . . . . . . . . . . . . . . . . . . 11

1.4 Vector and Scalar Identities ..................... 14

1.5 Integral Theorems . . . . . . . . . . . . . . . . 18

1.6 Bessel Functions . . . . . . . . . . . . . . . . . . . . 19

1.7 Spherical Bessel Functions . . . . . . . . . . . . . . 23

1.8 Legendre Functions . . . . . . . . . . . . . . . . . . . . 26

1.9 Stationary Phase . . . . . . . . . . . . . . . . . . 28

1.10 Matrices . . . . . . . . . . . . . . . . . . . . 30

1.11 Numerical Integration . . . . . . . . . . . . . . . 34

2 RESPONSE OF DYNAMICAL SYSTEMS 43

2.1 Time-Harmonic Response . . . . . . . . . . . . . . . 43

2.2 Transient Response . . . . . . . . . . . . . . . . . 47

2.3 Time-Harmonic Power Flow . . . . . . . . . . . . . 55

3 ACOUSTIC EQUATIONS

3.1 Differential Equation . . . . . . . . . . . . . 61

3.2 Plane Wave Solutions . . . . . . . . . . . . . . . . . . . 66

3.3 Green's Function in Cartesian Coordinates . . . . . . . . . . . . . 67 
3.4 Green's Function in Cylindrical Coordinates . . . . . . . . . . 70

3.5 Green's Function in Spherical Coordinates . . . . . . . . . . . 73

3.6 Arbitrary Source Distribution . . . . . . . . . . . . . 75

3.7 Arbitrary Boundaries . . . . . . . . . . . . . . . 77

3.8 Helmholtz Integral Equation . . . . . . . . . . . . . . . 77

4 SCATTERING FROM HARD AND SOFT STRUCTURES 83

4.1 Planar Surface . . . . . . . . . . . . . . . . 83

4.2 Spherical Surface . . . . . . . . . . . . . . . . . 88

4.3 Cylindrical Surface . . . . . . . . . . . . . . . . . . . 92

4.4 Axisymmetric Slender Body . . . . . . . . . . . . . . . . . 97

4.5 Monopole in Axisymmetric Channel . . . . . . . . . . . . 106

5 ACOUSTIC FINITE ELEMENTS

5.1 Variational Principle . . . . . . . . . . . . . . . 115

5.2 Finite Element Discretization . . . . . . . . . . . . . . . 119

5.3 Acoustic Finite Elements . . . . . . . . . . . . . . . . 121

5.4 Radiation Boundary Condition . . . . . . . . . . . . 123

5.5 Sources of Sound . . . . . . . . . . . . . . . 125

5.6 Axisymmetric Elements . . . . . . . . . . . . . . . . 126

6 ELASTIC EQUATIONS AND CONSTITUTIVE RELATIONS 133

6.1 Strain and Stress . . . . . . . . . . . . . . . . 133

6.2 Isotropic Displacement Equations . . . . . . . . . . . . . 136

6.3 Finite Element Variational Principle . . . . . . . . . . . . . 140

6.4 Fluid Constants . . . . . . . . . . . . . . . . . . . . . . . . . . . 144

6.5 Isotropic Elastic Constants . . . . . . . . . . . . . . . 144

6.6 Anisotropic Solid . . . . . . . . . . . . . . . . . . . . 148

6.7 Unidirectional Fibre Reinforcement . . . . . . . . . . . . . . 150

6.8 Thin Layered Composite . . . . . . . . . . . . . . . . . . . 151

6.9 Local to Global Transformation . . . . . . . . . . . . . . 155

6.10 Effective Constants of Symmetric Stack . . . . . . . . . . . 159

7 ACOUSTICS OF SPHERICAL SHELL 163

7.1 Equations of Motion . . . . . . . . . . . . . . 163

7.2 Mechanical Excitation . . . . . . . . . . . . . 165 
$7.3 \quad$ Acoustical Excitation . . . . . . . . . . . . . . . . . . . 171

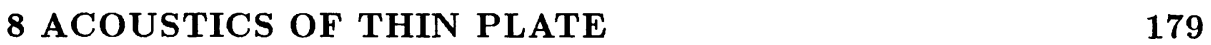

8.1 Equations of Motion . . . . . . . . . . . . . . 179

8.2 Mechanical Excitation . . . . . . . . . . . . . . . 180

8.3 Monopole Excitation . . . . . . . . . . . . . . . . . . . . . . . 189

8.4 Plane Wave Excitation . . . . . . . . . . . . . . . . . . . 191

8.5 Transient Sound Radiation . . . . . . . . . . . . . . 193

8.6 Frame and Bulkhead Stiffened Plate . . . . . . . . . . . . 198

8.7 Orthogonally Stiffened Plate . . . . . . . . . . . . . . 207

8.8 Plate with Point Attachments. . . . . . . . . . . . . . 213

8.9 Parallel Plates with Attachments . . . . . . . . . . . . 221

8.10 Plate with Periodic Resonators. . . . . . . . . . . . . . . 228

9 ACOUSTICS OF CYLINDRICAL SHELL 241

9.1 Equations of Isotropic Shell . . . . . . . . . . . . . . . . . . 241

9.2 Equations of Anisotropic Shell . . . . . . . . . . . . . . 244

9.3 Mechanical Excitation . . . . . . . . . . . . . . . 246

9.4 Monopole Excitation . . . . . . . . . . . . . . . . . . 253

9.5 Plane Wave Excitation . . . . . . . . . . . . . . . . . . . 259

9.6 Periodic Rib Stiffening . . . . . . . . . . . . . . . . . . 263

9.7 Axisymmetric Attachments . . . . . . . . . . . . . . . 273

9.8 Fluid Coating . . . . . . . . . . . . . . . . . . . . . 278

10 SPHERICALLY LAYERED MEDIA 283

10.1 Introduction . . . . . . . . . . . . . . . . . . 283

10.2 Acoustic Fluid Layer . . . . . . . . . . . . . . . . 284

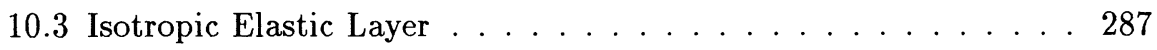

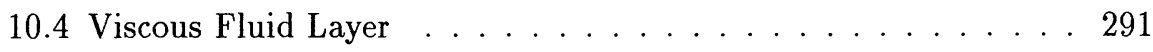

10.5 Assembly of Elements . . . . . . . . . . . . . . . . . 293

10.6 Mechanical Excitation . . . . . . . . . . . . . . 294

10.7 Acoustical Excitation . . . . . . . . . . . . . . . . 295

10.8 Numerical Examples . . . . . . . . . . . . . . . . . . . . 297 
viii

11 PLANAR LAYERED MEDIA 301

11.1 Introduction . . . . . . . . . . . . . . . . . 301

11.2 Acoustic Fluid Layer . . . . . . . . . . . . . . . . . . . . . . . . . . . . . . . . . . . . . . . .

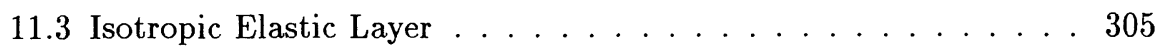

11.4 Orthotropic Elastic Layer . . . . . . . . . . . . . . . 311

11.5 Viscous Fluid Layer . . . . . . . . . . . . . . . . 317

11.6 Assembly of Elements . . . . . . . . . . . . . . . . . . 319

11.7 Mechanical Excitation . . . . . . . . . . . . . . . 320

11.8 Monopole Excitation . . . . . . . . . . . . . . . . 325

11.9 Plane Wave Excitation . . . . . . . . . . . . . . . . . . . . 329

11.10Low Frequency Sound Propagation . . . . . . . . . . . . 333

12 CYLINDRICALLY LAYERED MEDIA 343

12.1 Introduction . . . . . . . . . . . . . . . . . . 343

12.2 Acoustic Fluid Layer . . . . . . . . . . . . . . . . 345

12.3 Isotropic Elastic Layer . . . . . . . . . . . . . . . . 347

12.4 Orthotropic Elastic Layer . . . . . . . . . . . . . . 354

12.5 Viscous Fluid Layer _ . . . . . . . . . . . . . . 359

12.6 Assembly of Elements . . . . . . . . . . . . . . . 361

12.7 Mechanical Excitation . . . . . . . . . . . . . 362

12.8 Monopole Excitation . . . . . . . . . . . . . . 366

12.9 Plane Wave Excitation . . . . . . . . . . . . . . . . . . 369

13 SIMPLY SUPPORTED CYLINDER 373

13.1 Isotropic Thin Cylinder . . . . . . . . . . . . . . 373

13.2 Point Force Excitation . . . . . . . . . . . . . . . . 376

13.3 Plane Wave Excitation . . . . . . . . . . . . . . . . 381

13.4 Anisotropic Layered Cylinder . . . . . . . . . . . . . . . 385

14 FINITE AXISYMMETRIC STRUCTURE 395

14.1 Introduction . . . . . . . . . . . . . . . . . . . . . . . . . . . . . . . . . . . . . . . . . . . .

14.2 Fourier Series . . . . . . . . . . . . . . . . . . . 397

14.3 Helmholtz Integral Equation . . . . . . . . . . . . . . . . . . . . . . . . . . . . . . . . . . . . .

14.4 Far Field Acoustics . . . . . . . . . . . . . . . . . . . . 403

14.5 Fluid-Structure Equations . . . . . . . . . . . . . . 406

14.6 Conical Shell Finite Element . . . . . . . . . . . . . . . 408 
14.7 Axisymmetric Solid Finite Element . . . . . . . . . . . . . . . 414

14.8 System Dynamic Stiffness . . . . . . . . . . . . . . . . . . . . . . . . . . . . . . . . .

14.9 Numerical Examples . . . . . . . . . . . . . . . . . 423

LIST OF COMMONLY OCCURRING SYMBOLS $\quad 429$

INDEX $\quad 433$ 


\section{This page is intentionally left blank}




\section{PREFACE}

The mathematics of sound radiation from, and sound scattering by, elastic structures has received much attention in the latter half of this century due to its relevance to the problem of detecting and classifying submarines and other submersibles. The theoretical work described herein is substantially a compilation of our research interests for the Navy on the acoustics of basic elastic structures excited by mechanical forces and acoustic sources. It is not intended as a comprehensive treatment of the subject for which even a list of textbooks and research publications is far too lengthy to record here. The standard reference work on theoretical structural acoustics is the textbook "Sound, Structures, and Their Interaction", published by the MIT Press, and authored by Junger \& Feit. The Journal of Sound and Vibration and the Journal of the Acoustical Society of America are the main repositories of refereed papers.

While the textbook has been written primarily as a reference work at a postgraduate level, experience has shown that undergraduates are well able to cope with most aspects provided they are supervised accordingly. The theoretical methods, developed originally for Naval noise control problems, should also find civil application in the acoustic modelling of novel structures fabricated from both fibre reinforced and isotropic materials, such effort being increasingly desirable and necessary in this noisy world. The textbook should be a useful source of information for those scientists who need to develop skills in theoretical and/or numerical modelling in dynamics and acoustics, and it is hoped that it will also be a profitable source of material for scientists whose research interests lie elsewhere in continuum mechanics.

The first edition of any sizeable mathematical publication is likely to contain algebraic and typographical errors. The responsibility for those here is ours alone. When formulae are extracted from published literature it is generally advisable to check them against originals and also, if possible, to re-work the mathematics. 
xii

E.A. Skelton

Mathematics Department

Imperial College of Science, Technology and Medicine

London, SW7 2BZ

J.H. James

Brynteg House, High Street

Mountain Ash

Mid Glamorgan, CF45 3PB

May 1997 


\section{ACKNOWLEDGEMENTS}

Much of the work described here is contained in Ministry of Defence technical reports and memoranda written by the authors and colleagues over the years 1974-1994. Our thanks to the Procurement Executive, Ministry of Defence for providing funding for that research as part of an underwater acoustics research programme. The Defence Research Agency provided access to reports and software, for which we are grateful to C.J. Jenkins, D. Ealey and librarian J. Sawyer. Particular thanks are due to E.J. Clement who ably has assisted us over the years. Work done with ex-colleagues S.J. Ansley, G. Jones and V. Burke is also included here. Students John Melotte, Julie Pestell, William Spicer, Sherrie Lester, Nicola White and James Mason worked gainfully during their summer vacations. Navy scientists A.L. Kendrick, G. Barber, J. Cook, A.N. Hicks, D. Emery, G. Alker, A. Baird, G. Jones, A. James, and C. Jenkins have supported a background of theoretical modelling as a necessary and valuable input to applied research programmes. The research output of University scientists has also provided a worthy contribution: B.R. Mace, M. Petyt, C.R. Fuller and F.J. Fahy, working at the Institute of Sound and Vibration Research, have provided quality research on wave propagation in fluid-loaded plates and shells; I.C. Mathews and research students at Imperial College have provided up to date expertise in finite element analysis of fluid-structure interaction problems. A.G.P Warham, G.F. Miller, R. Borland and A.J. Burton, at the National Physical Laboratory, have always been happy to take on difficult theoretical problems. We are grateful to the publisher Academic Press Limited London for permission to use material from certain papers published in The Journal of Sound and Vibration. Finally, we apologize to those who perceive that their work has been omitted or not properly acknowledged; it sometimes can be difficult to attribute credit and/or priority because similar work has sometimes been carried out in many research organizations, and not always published in refereed journals or publicly released technical reports. 